\title{
Chronic fatigue syndrome and children ${ }^{\dagger}$
}

\author{
Simon Wessely
}

This issue of the Bulletin contains two brief papers on the subject of chronic fatigue syndrome (CFS) in childhood. The first is a study of the outcome of a small series of patients followed into adulthood (Khawaja \& Van Boxel, 1998). The results suggest that most had done well, but a few had not. Those with good outcomes had participated in a rehabilitation package based on cognitive-behavioural principles. Two had done particularly badly, and had not taken part in the programme. The authors cannot say if taking part in the programme was the factor distinguishing good and poor outcome, but treatment did no harm, and may have been of benefit.

In the second paper general practitioners were asked about their views on CFS in childhood (Richards \& Smith, 1998). The results showed that about half recognised the existence of CFS in children. Eighty-three children had been diagnosed with the condition in the preceding year. This kind of data cannot give any information on prevalence, but only on diagnostic practices and recognition. We know from the adult literature that many of those who fulfil accepted international criteria for CFS are not labelled by either themselves or their doctor as such, while conversely many of those who are labelled as suffering from CFS or its vernacular equivalents, do not fulfil the criteria. Key informant surveys, such as those conducted by Richards \& Smith, cannot give valid epidemiological data, and the authors, as in the previous paper, behave with commendable restraint in their conclusions.

So why did the editor request an editorial? It was because even in an emotive area, the subject of CFS and children is particularly sensitive. Recent newspaper headlines, such as "Schools swept by ME plague" highlight the dangers of uncritical reporting. Good quality research into CFS and children is sadly rare, and there is no consensus or firm guidance on its nature, prevalence, treatment or outcome. The recent report from the three medical Royal Colleges

'See pp. 198-202 and 203-206, this issue. outlined what was considered good practice in the management of chronically fatigued children (Royal Colleges of Physicians, Psychiatrists and General Practitioners, 1996), practices which closely resemble those of Khawaja \& Van Boxel, but in the absence of randomised trials, these can only be guidelines. Yet there are numerous corners of medicine yet to be fully illuminated by the light of good research-should we worry about this topic?

We should. In the absence of sound research. anecdote, prejudice and passion can sometimes achieve undue prominence. We know little about the nosological status of CFS in children. We do not even know if there is a recognisable entity discrete from other known sources of morbidity. I suspect there is, but we cannot be sure. All general practitioners are familiar with the child making a slow recovery from glandular fever should that child be considered a case of CFS? All are also familiar with children unable to keep up with the demands, educational or social, made upon them - is that CFS? Childhood depression is only now being recognised - where are the boundaries between that and CFS? The answer is we do not know at present. But does it matter if we labelled a child as having CFS, or 'ME' as it will probably still be called? It might. The label itself is not the problem, but what follows. If the label is used as a way of stopping increasingly fruitless diagnostic investigations. and instead taking a careful look at what actually is going on, while acknowledging the reality of the problem, all well and good (Marcovitch, 1997). If it leads to the form of pragmatic rehabilitation endorsed in a series of publications, then again nothing has been lost and much gained. But there is an alternative. If the label of CFS or ME is felt to imply the child is suffering from some mysterious, hidden but persistent disorder of the immune system, or to be in the grip of an invisible but malevolent infection, then eyes can be closed to other sources of distress, and attempts to rehabilitate the child in the context of family and school ignored. One can still encounter statements such as 'ME in children lasts an average of four and a half years'. This can become a self-fulfilling 
prophecy. If that had only happened once, it would be a source of concern, but the impression among the paediatric community is that this is not an infrequent occurrence, in which misinformation and entrenched attitudes conspire against recovery. American paediatricians recently wrote that dangers exist in labelling children with a disease which "has profound implications for their level of functioning in society, especially when the disease is not well defined in childhood and when there are no irrefutable laboratory markers for it" (Carter et $a l, 1993)$. Yet it is all too often seen as persistent or even incurable. One author, who is a firm and committed champion of CFS in adults, has recently suggested the diagnosis should never be made in children for these reasons (Plioplys, 1997). He argues that in all the patients he has seen, there was an alternative, and by implication more accurate and more appropriate. diagnosis available.

I do not share that opinion because there is uncertainty on the subject, and whatever our views, children are being labelled as having this problem, and need treatment. Anyone who deals regularly with adults or children with this condition, whatever it may be, will also know that challenging what is often a firmly held belief by patient or family is inappropriate, counterproductive, and almost invariably leads to a breakdown of the doctor-patient relationship. Establishing a therapeutic alliance is not a preliminary to treatment, but is part of treatment itself (Wilson et al, 1994; Wessely et al, 1998). Suggesting that the label be abolished is unlikely to be effective, and will only worsen the plight of those currently suffering. Instead it is more appropriate to ask that those who contemplate using the diagnosis in future do so with reflection and humility, and only after a proper consideration of the dangers of uncritical or over enthusiastic espousal of this ambiguous diagnosis.

Whether it exists or not is not the issue. Doctors need to learn how to manage children and families who present in this fashion.
Fortunately, it is my experience that paediatricians in this country are usually more than able to do just that, perhaps because paediatricians instinctively avoid the mind-body traps that so dog their adult counterparts. It is insulting to most paediatricians to be told that children exist in families, that social, psychological and physical factors all conspire to create illness, that children should be kept off school for the shortest practical time, and that supportive, active and empathic management cures most ills.

The Royal College of Paediatricians and the relevant sections of the Royal College of Psychiatrists have yet to give a firm lead on this subject. It is time for them to do so.

\section{References}

Carter, B., Edwards, J. \& Marshall, G. (1993) Chronic fatigue in children: illness or disease? Pediatrics, 80. 163.

KhaWAJA, S. \& VAN Boxel, P. (1998) Chronic fatigue syndrome in children: seven-year follow-up study. Psychiatric Bulletin, 22, 198-202.

MARCOVITCH, H. (1997) Managing chronic fatigue syndrome in children. Brttish Medical Journal, 314, 1635-1636.

PuOPLYS, A. (1997) Chronic fatigue syndrome should not be diagnosed in children. Pediatrics, 100, 270-271.

RICHARDS, J. \& SMITH, F. (1998) Chronic fatigue syndrome in children and adolescents. General practitioners' experience of the problem and their views about its treatment. Psychiatric Bulletin, 22, 203-206.

Royal Colleges of Physicians, Psychiatrists and General PractTIONERS (1996) Chronic Fatigue Syndrome: Report of a Joint Working Group of the Royal Colleges of Physicians, Psychiatrists and General Practitioners (Council Report CR54). London: Royal College of Physicians.

Wessely, S., HOTOPF, M. \& SHARPE, M. (1998) Chronic Fatigue and its Syndromes. Oxford: Oxford University Press.

WILSON, A., HICKIE, I., LLOYD, A., et al (1994) The treatment of chronic fatigue syndrome: science and speculation. American Joumal of Medicine, 86, 544-549.

Simon Wessely, Academic Department of Psychological Medicine, King's College School of Medicine, 103 Denmark Hill, London SE11 6BY 